\title{
A ARTE DE FESTEJAR DA ALTERNÂNCIA DA FESTA E DE SUAS EXPRESSÕES MATERIAIS
}

Juliana Aparecida Garcia Corrêa (UEMG)

Este artigo analisa as expressões materiais de festas tradicionalmente realizadas pelos membros de uma irmandade do rosário localizada no Estado de Minas Gerais. Temas tais como criação, performance, materialidade perpassam o artigo, que se articula a partir do princípio maussiano da sazonalidade da vida social, sobretudo para pensar a alternância da festa interpretada em suas expressões materiais.

\section{FESTA; CULTURA POPULAR; ESTÉTICA; OBJETOS} MATERIAIS.

CORRÊA, Juliana Aparecida Garcia. A arte de festejar: da alternância da festa e de suas expressões materiais. Textos escolhidos de cultura e arte populares, Rio de Janeiro, v.10, n.1, p. 183-199, mai. 2013. 


\section{THE ART OF CELEBRATING \\ ON THE CHANGES IN PARTIES \\ AND THEIR MATERIAL EXPRESSIONS}

Juliana Aparecida Garcia Corrêa (UEMG)

This article analyzes material expressions of festivities traditionally held by members of a brotherhood of the rosary in the state of Minas Gerais. Themes such as creation, performance, and materiality pervades this article, which is based on the Maussian notion of social life seasonality, especially to think of party changes interpreted in their material expressions.

PARTY; POPULAR CULTURE; AESTHETICS; MATERIAL OBJECTS.

CORRÊA, Juliana Aparecida Garcia. A arte de festejar: da alternância da festa e de suas expressões materiais. Textos escolhidos de cultura e arte populares, Rio de Janeiro, v.10, n.1, p. 183-199, mai. 2013. 


\section{QUESTÕES PRELIMINARES}

A festa vista como acontecimento coletivo ultrapassa o sentido da comemoração e atua na formação dos vínculos que fundamentam a experiência humana coletiva. Ela marca histórias pontuando e regulando o curso da vida das pessoas. A festa é índice de temporalidade, marca os tempos fortes e culminantes para a coletividade. Ilustração disso encontramos nos calendários, que destacam domingos e feriados [dias de festa]. De fato, como observa DaMatta (1983), temos um modo especial de sociabilidade, pois somos submetidos às regras de um país carnavalizado, logo, às regras de um modelo de festa. Para o autor, o carnaval é a maior festa brasileira, sendo também um modo privilegiado de dramatização da vida social. Características como rompimento temporal da vida cotidiana, inversão hierárquica da ordem social e invenção de papéis rituais são demarcações que nos fornecem pistas para investigar estruturas de outros modelos de festas brasileiras, sem perder de vista suas diferenciações substantivas.

Como bem salientado por Perez (2004, p. 16), trata-se de entender a "festa como perspectiva" trata-se, portanto, de um mecanismo festivo atuante em todas as festas. Segundo a autora,

O fato (leia-se festas instituídas) não se confunde e não se sobrepõe ao mecanismo. A desconstrução, desrealização do real instituído e a decorrente abertura para o imaginário, isto é, o não instituído, operação fundamental realizada pelo mecanismo festivo, é uma virtualidade que pode eclodir ou não no interior das festas instituídas.

Assim, quero considerar primeiramente a proposição de Perez (2002, p. 17) de tomar a festa como, "uma forma lúdica de sociação e como fenômeno gerador de imagens multiformes da vida coletiva, que busca mostrar como o vínculo social pode ser gerado a partir da poetização e estetização da experiência humana em sociedade". Assim o estudo da festa fornece elementos para pensar as bases constitutivas dos vínculos que fundamentam a experiência humana nas dimensões da vida social (regra estrutural) e da vida coletiva (ordem dos sentimentos). Admitimos a noção de estrutura da vida social, entendida em seu dinamismo, incorporando o conceito sociação, como processo permanente do vir a ser social que diz respeito à "forma" realizada de incontáveis maneiras diferentes pelas quais os indivíduos se agrupam (SIMMEL apud PEREZ, 2002, p. 18).

Tal proposta aproxima o estudo da festa dos domínios da estética, do lúdico, do sonho e da arte. A teoria seminal de Durkheim (1985) fornece bases elementares para a compreensão da festa como lugar privilegiado de exaltação dos sentimentos coletivos. Para o autor, a festa é agrupamento único em estado de 
exaltação geral em torno de algo ou alguém, gera efervescência coletiva, exaltação das paixões comuns, produzindo a comunhão de sentimentos que possibilita a transgressão de normas e o reforço dos vínculos. De outro modo, podemos acentuar o caráter do estar junto na festa, a partir das reflexões trazidas por Mauss (1981, p. 334) em seus estudos sobre rituais funerários autralianos. Gostaria de indicar assim a centralidade da festa na experiência humana. É, pois, por meio da incorporação de três elementos - corpo, consciência individual e coletividade - que a festa expressa "a própria vida, o homem, sua vontade de viver ele mesmo sua vida".

Foi tal expressão da vida coletiva que me aproximou da comunidade de Justinópolis, onde conheci uma irmandade de Nossa Senhora do Rosário, que recebe o próprio nome do distrito. Instalada há 115 anos, quando o local ainda recebia o nome de Campanhã, a irmandade anualmente realiza suas festas religiosas aos santos, prática advinda do período colonial mineiro. Ao que parece, a Irmandade de Nossa Senhora do Rosário de Justinópolis provém da Irmandade dos Arturos, que é uma descendência da irmandade de Ibirité, uma das mais antigas de Minas Gerais (CORREA, 2009). Trata-se aqui das festas dos santos padroeiros, o que, como bem demonstra Zaluar (1983, p. 116-117), é expressão singular do catolicismo popular brasileiro. Constituindo atividade sem a participação da Igreja, sua forma expressiva é eminentemente prática, e sua linguagem, inserida no conjunto de uma ação ritual. É nos rituais e "na maneira de conceber as relações entre os homens e os santos que está simbolicamente expresso o código que rege as relações dos homens entre si". Voltando a Justinópolis, trata-se, assim, de festas que constituem a forma privilegiada de vida coletiva desse grupo: as festas de Nossa Senhora do Rosário, são Benedito, são Sebastião, a caravana dos santos reis e a folia de são Sebastião, festas tradicionais do Estado de Minas Gerais.

Nota-se que essas festas são semelhantes às já catalogadas como tradicionais no circuito religioso popular mineiro segundo Martins (1991). A elas corresponde um calendário anual que aqui classifico em quatro ciclos festivos, conforme o quadro 1 :

\begin{tabular}{|l|l|l|l|}
\hline Ciclos & $\begin{array}{l}\text { Meses de } \\
\text { duração }\end{array}$ & $\begin{array}{l}\text { Formas de } \\
\text { manifestação }\end{array}$ & Santos de devoção \\
\hline Marial & Abr.-jun. & Coroações & Virgem Maria \\
\hline Junino & Jun.-ago. & Quadrilhas & São João, santo Antônio, são Pedro \\
\hline Rosário & Set.-nov. & Congados & $\begin{array}{l}\text { Nossa Senhora do Rosário, santa Ifigênia, } \\
\text { são Benedito }\end{array}$ \\
\hline Natalino & Dez.-fev. & Folias & Santos reis, são Sebastião \\
\hline
\end{tabular}

Quadro 1: Ciclos festivos tradicionais de Minas Gerais 
Aqui, o ponto que nos interessa é a alternância de ritmos que a festa produz e os papéis rituais que a ela se associam. Conforme se verifica trata-se de ciclo que inclui outros ciclos festivos. Interessa-nos em específico as festas do ciclo do rosário (reinados) e do ciclo natalino (reisados ou folias de reis). Os ciclos do rosário e de reis são definidos e reconhecidos pelos membros da irmandade de Jusitnópolis conforme o quadro 2:

\begin{tabular}{|l|l|l|l|}
\hline Ciclos & $\begin{array}{l}\text { Meses de } \\
\text { duração }\end{array}$ & $\begin{array}{l}\text { Formas de } \\
\text { manifestação }\end{array}$ & Santos de devoção \\
\hline Rosário & Jan.-nov. & Congados & $\begin{array}{l}\text { São Sebastião, são Benedito, Nossa Senho- } \\
\text { ra do Rosário }\end{array}$ \\
\hline Reis & Dez.-fev. & Folias & $\begin{array}{l}\text { Santos reis, são Sebastião, Nossa Senhora } \\
\text { da Luz }\end{array}$ \\
\hline
\end{tabular}

Quadro 2: Ciclos festivos de Justinópolis

O ciclo maior (anual) comporta dois pequenos ciclos (rosário e reis) e cada um deles possui três festas dedicadas aos santos padroeiros. As do ciclo do rosário, chamadas de festas de reinado acontecem no terreiro da irmandade. Realizada no domingo próximo ao dia 21 de janeiro, a festa de são Sebastião, padroeiro da coletividade, recebe tanto foliões quanto congadeiros. Ela é peculiar, pois pertence aos dois ciclos. Sendo "duas festas em uma", as pessoas vivem duas encenações com transmutação de papéis. No dia de são Sebastião, o terreiro conta com as guardas de congo e de moçambique e a caravana dos santos reis da irmandade, e recebe ainda a visita de outras folias e de cavalgadas que se reúnem para devoção ao santo.

A festa de são Benedito acontece no segundo domingo de maio. Muito popular e reconhecido como "santo de pretos", em sua festa comemora-se o dia da libertação dos escravos (13 de maio), exaltado pelos membros da irmandade numa bela intervenção cênica na praça da igreja matriz da cidade. A importância dessa festa no ciclo-circuito se dá porque a ela corresponde o dia da coroação dos reis festeiros pelos reis congos, responsáveis pelo acúmulo das economias necessárias para a realização da festa de outubro.

Encerrando o circuito de festas desse ciclo, a festa do segundo domingo de outubro é oferecida pelos reis festeiros aos reis congos em homenagem a Nossa Senhora do Rosário, mãe dos congadeiros. Sendo a festa mais importante, tem três dias de duração e recebe o maior número de visitantes, incluindo guardas vindas de diferentes regiões do estado. 
O ciclo do rosário, aberto com a coroação dos reis congos em janeiro, só é encerrado após a realização das três festas e com a respectiva descoroação em novembro, tudo na batida do candombe. O período das festas do reisado é iniciado pela montagem da lapinha (construção do presépio) no dia 8 de dezembro, terminando com sua desmontagem em 2 de fevereiro.

Ao reisado de Justinópolis corresponde um ciclo de duração menor quando comparado ao reinado. A irmandade, entretanto, permanece festejando todas as noites durante o período. $\mathrm{E}$, se comparado às demais festas de reisado do estado, Justinópolis tem ciclo festivo maior, pois não termina no dia de reis, como de costume as folias mineiras, estendendo-se até o dia de Nossa Senhora da Luz.

Cada uma das três festas de reisado marca uma das três etapas que corresponde a um trecho da caminhada dos reis. Realizada na casa de algum dos devotos, as festas dos santos reis e de Nossa Senhora da Luz não têm lugar fixo, variando de ano para ano. A festa de são Sebastião, por pertencer simultaneamente ao congado e ao reisado, diferentemente das outras duas, acontece sempre no terreiro do congado. Durante todo o período, a caravana percorre diferentes casas, visitando as lapinhas, cantando versos e recolhendo doações. Cada vez que a folia bate numa casa, ela conta trechos da peregrinação do reis magos, narrativa que tem no texto bíblico sua escritura principal, mas que recebe algumas pinceladas de outros eventos míticos, acrescentando coloração diferente do modelo inicial (GOMES, PEREIRA, 1994).

A primeira fase da folia sai no ritmo das batidas de caixa de nome Rei Novo, narrando o ciclo da boa nova ou nascimento. É chamado de giro de ida, pois corresponde à saída dos reis de suas terras até a chegada à lapinha. Começa na virada de 24 para 25 de dezembro, estendendo-se até 6 de janeiro, quando se realiza a festa de reis. A segunda etapa indica a chegada dos reis na lapinha, o oferecimento de seus presentes e suas coroações pela Virgem Maria. Nessa etapa a folia troca de bandeira, muda suas batidas de caixa e os versos cantados, seguindo com estes até 21 de janeiro, na festa de são Sebastião. A terceira etapa da folia acompanha os ritmos de nome Rei Velho, começa com a apresentação do menino Jesus ao templo e narra o retorno dos reis magos a suas terras. A festa de encerramento do ciclo do reisado é chamada de festa de pifania; diferentemente do que ocorre no costume cristão, a epifania na irmandade não se dá no dia de reis, sendo comemorada em 2 de fevereiro, em homenagem a Nossa Senhora da Luz.

Segundo Seu Dirceu ${ }^{1}$, a festa da pifania é a de encerramento, a festa de arremate da folia. É a maior e representa a viagem de volta dos reis, o último encontro antes da despedida final e do retorno definitivo para suas terras. 
A festa aqui aproxima-se do rito e, nessa medida, é compreendida não como representação, mas como realidade vivida, paradoxo produtivo, como drama social em que comportamentos constituem unidades sociotemporais mais ou menos fechadas em si mesmas (TURNER, 1969).

É desse modo que a irmandade de Justinópolis segue sua vida, com muita festividade e muito trabalho. Eles se quebram e requebram (na festa e fora dela), ludibriando os tempos do trabalho e os tempos do lazer.

\section{ALTERNÂNCIA E MATERIALIDADES FESTIVAS}

Assumimos que, de maneiras inusitadas, a festa atua sobretudo como um operador de ligações. E assim, creio que chegamos ao ponto que me permite retomar as festas e lançar outro olhar para as questões preliminares deste artigo. Tomo a liberdade de usar, ainda que de modo diferente, o argumento utilizado por Mauss e Callois, entre outros. Adoto aqui a teoria maussiana da sazonalidade não como ilustração da vida religiosa, mas como princípio geral de alternância da vida social e da experiência coletiva. A passagem a seguir é um convite para pensar o princípio da alternância como regra para a experiência humana.

A vida social não se mantém no mesmo nível nos diferentes momentos do ano, mas passa por fases sucessivas e regulares de intensidade crescente e decrescente, de repouso e de atividade, de dispêndio e reparação (MAUSS, 1974: 324).

Nota-se que alguns elementos compõem sequências rituais que, por sua vez, dão forma à estrutura das festas de santos. Em cada festa, eles adquirem diferentes atributos, podendo repetir-se em diferentes sequências do mesmo ciclo e retornar de outro modo, no ciclo seguinte. Conforme sugiro a seguir é a circulação dos objetos que confere o caráter de alternância, dando à estrutura das festas sua forma cíclica. Característica de suma importância para o artigo.

No que diz respeito à compreensão das sequências é importante enfatizar que os elementos camdombe, lapinha, bandeiras e reis configuram sequências rituais no início e no final das festas. Assim, para cada sequência de entrada na festa corresponde uma sequência de saída idêntica, porém inversa. O candombe é tocado para coroação dos reis congos, celebrando a abertura do ciclo de festas do reinado. Ele novamente é tocado para descoroação no encerramento desse ciclo. A lapinha (presépio) é montada no início do ciclo das festas do reisado e é desmontada no seu fim. Já o elemento bandeira recebe atributo em relação ao período festivo, ocorrendo no início e no final de cada uma das três festas de ambos os ciclos. Os outros elementos fazem referência ao dia da festa e se 
repetem em cada dia no caso das festas do congado e várias vezes em cada noite de saída da folia.

O toque do candombe e a montagem da lapinha constituem o fundamento da festa, pois evocam a cena fundante, com que tudo começou. Assim, eles são presença obrigatória para a realização da abertura e do encerramento dos ciclos festivos correspondentes. Como informa Seu Dirceu ${ }^{2}$, as festas da irmandade falam sobre reis e sobre realezas de modos distintos; por exemplo, o candombe evoca o fundamento dos reis congos africanos, e a lapinha, o fundamento bíblico dos reis magos. A realeza é exibida de formas diferenciadas nas festas: no reinado os reis são solenes e consagrados pela utilização da coroa e do cetro; no reisado, eles são reconhecidos pelo uso de suas máscaras.

O fundamento da festa é transmitido pela oralidade, entoado pelos cantos acompanhados das danças que se fazem presentes em toda a sequência festiva, dando cor, calor e agitação à festa. Euridiana Souza (2009) lembra brilhantemente como a música é mana, essa substância manejável, mas independente, exatamente pelo poder que tem de dar valor a coisas e pessoas. Acompanhada pelos gestos, responde sobretudo a uma experiência que não está a serviço de nada, apenas à necessidade de gesticular e de produzir agitação. A eficácia do gesto, como aponta Duvignaud $(1983$, p. 88) se dá não só porque ele aparenta um si da existência e nos engaja na vida imaginária, mas, sobretudo porque extrai o mito da linguagem e o substitui na rede de uma comunicação. Assim canta-se e dançase muito nas festas. A festa, esse dom do nada, é movimento corporal. Além de tentar decifrar os significados dos cantos e das danças, importante é frisar a necessidade obrigatória de eles acontecerem. É o que Perez (2002) toma como significante flutuante.

Os cantos do reinado são entoados pelos capitães e pelas guardas. Cada guarda possui seu canto e seu movimento específico realizado pelos ritmos produzidos pelos instrumentos. Além das caixas de percussão, contam com um reco-reco e um patangome, instrumento típico de congado que consiste de duas calotas de carro unidas em que se colocam grãos de arroz, e cujo som é igual ao de chocalho. Os toques podem ser serra acima, serra abaixo, repicado e dobrado. A variação desses toques é dada pelo tempo empregado na frase rítmica em cada um deles.

Cada sequência ritual pede um toque de caixa específico. Alguns deles são definidos previamente, outros determinados pelo capitão da guarda na sequência da festa. É sabedoria exclusiva dos mestres congadeiros.

Nas festas do ciclo de reinado as danças ficam a cargo das guardas. A guarda de moçambique apresenta danças com gestos mais contidos e solenes, com 
os troncos curvados e os pés firmes no solo; a guarda de congo, por sua vez, dança para o alto, realizando gestos mais soltos e amplos, como se se erguesse para o céu. Nas festas do ciclo de reisado são os reis que exibem suas danças, variando entre fagote, fagote para lundu e lundu, entre danças mais lentas e suaves para sapateados firmes e marcados.

De acordo com Gennep (1978, p. 35), há uma regra geral de ocupação de território cujos limites são marcados por um objeto que expressa interdição de caráter mágico-religioso. Postes, mastros, pórticos, pedras ou estátuas, no mundo clássico, ou outros objetos mais simples, hoje em dia, são colocados para demarcar esses limites e normalmente vêm acompanhados por um rito de consagração. É desse modo que compreendo as sequências rituais de levantamento dos mastros e retiradas das bandeiras. As bandeiras consagram o local sagrado, compondo o cenário festivo, elas também anunciam o motivo da festa, seja circulando nas mãos de quem tem o papel de as conduzir, fixadas nos mastros erguidos no terreiro. Sua função no rito (se função existe, bien sûr) é anunciativa. Isso me ensinou seu Dirceu ${ }^{3}$, contando o que, em sua opinião, poucos conhecem ou se interessam em saber:

A história conta da primeira bandeira que foi levantada, a bandeira de são João que se deu no encontro de Maria e Isabel. Maria, que já estava grávida saiu em visita a Isabel que ia dar à luz e morava muito longe, escondida no meio do mato. Isabel, após dar à luz João, elevou um estandarte bem no alto para anunciar às pessoas que o primo de Jesus havia nascido. A bandeira diz a anunciação do nascimento. Quando tem uma bandeira levantada, todos sabem que alguma coisa está acontecendo.

As festas do reinado podem ter várias bandeiras, mas, três são indispensáveis: a de aviso, a de guia e a do santo venerado. Após o levantamento da bandeira de aviso, começa uma novena que termina com o levantamento da bandeira de guia, com a imagem de Nossa Senhora da Guia. Em Justinópolis ela é sempre colocada no quintal da casa do capitão Adelmo, onde as guardas se reúnem e são "guiadas" durante os rituais da festa. A bandeira do dia, também obrigatória, corresponde ao santo venerado. É levantada no terreiro na madrugada que antecede a festa. A essas três acrescentam-se outras, chamadas bandeiras de promessas que, se juntando ao grupo, preenchem com grandiosidade todo o perímetro do terreiro, colorindo e alegrando o espaço festivo.

No reisado há três bandeiras, que indicam a fase que está batendo a folia. Na primeira batida ela sai com a figura de dois reis, pois, de acordo com mestre Dirceu, Melquior havia sido deixado para trás. Logo após o encontro com o 
primeiro presépio a caravana segue com a bandeira completa com os três reis, o menino e a estrela-guia. A bandeira é trocada até o dia da festa de são Sebastião, trazendo estampada a imagem do santo. Após a festa ela novamente é trocada, carregando então a ilustração da Nossa Senhora da Guia. O levantamento das bandeiras do congado e a troca de bandeiras da folia são realizados sem obrigatoriedade de as pessoas estarem com suas fardas, exceto a bandeira do dia da festa. No caso dos reis congos, eles não precisam usar suas coroas, e no caso dos reis magos eles também não precisam usar suas máscaras. É na alvorada que as pessoas se transformam, vestem suas fardas, pegam seus instrumentos, preparam-se para assumir seus respectivos papéis, mantidos por todo o dia da festa.

De fato, a alvorada corresponde a um procedimento de diferenciação, como acrescenta seu Dirceu, as pessoas deixam de ser chamadas por seus nomes e passam a ser nominadas pelas funções no ritual, como, por exemplo, capitão regente do congado, mestre da folia de reis. Assim ela nos introduz na performance festiva, esse conjunto de atos de mudança de vestuário, exteriorizado pelos materiais impressos no corpo, integrando uma sequência que "faz o grupo sair do mundo profano e o agrega ao mundo sagrado" (GENNEP, 1978, p. 154).

Nas festas do congado as funções estão dispostas em hierarquia ritual formada primeiramente por reis, rainhas e princesas do reinado, seguidos pelo capitão-mor, pelo capitão regente, pelo capitão da guarda de moçambique e pela capitã da guarda de congo. Por último, os caixeiros e os dançarinos das guardas formam o corpo de baile da festa. A hora mais importante da alvorada é quando os reis recebem suas coroas; a coroação é chamada também de tirada dos reis. ${ }^{4}$

Os reis e as rainhas do congado devem portar coroas, cetros e roupas finas. Os capitães usam fardas e portam bastões e espadas. A guarda de moçambique deve usar fardamento branco e azul formado por saiote, blusa, lenço na cabeça, gungas nos pés e no tronco rosário disposto em forma de X. A guarda de congo não veste cor definida nem modelo fixo, não usa gungas, e o rosário cruza o tronco de um ombro até o quadril do lado oposto.

A hierarquia ritual do reisado é menos complexa do que a do reinado. Iniciada pelos três reis magos e seguida pelo mestre, é finalizada pelo coro de seis vozes e violas. As fardas dos violeiros não têm cores ou desenhos específicos, a uniformidade é dada pelo uso de calça social, sapatos pretos e chapéu que não pode faltar na cabeça. A roupa e a máscara dos reis, entretanto, são de cores determinadas. O rei Melquior usa máscara negra e veste-se de vermelho; o rei Baltazar usa barba e veste-se de branco; e o rei Gaspar usa máscara de jovem e veste-se de preto. A alvorada não é dotada de tanto rigor e seriedade como no reinado. De modo mais informal, os integrantes da caravana vão chegando e se reu- 
nindo na casa do mestre para aquecer suas vozes e violas. Não há na sequência algo que corresponderia à coroação dos reis, mesmo porque a ação de colocar e retirar as máscaras é realizada em separado, mantendo em segredo a identificação das pessoas.

As procissões exibem o caráter público da festa, característica peculiar das festas do catolicismo popular brasileiro, tido como processional. Reconhecidas como atividades urbanas mais antigas, apresentam um rito-espetáculo, como observa Perez (2002, p. 43), mostrando uma maneira singular de viver em sociedade, de ver o mundo e de com ele relacionar, pois

Revelam uma sociedade que desde o começo vive do espetáculo, das mudanças e da fusão de vários códigos e registros intermutáveis, que ri de si mesma, que poetiza as relações dos homens consigo mesmo e dos mundos nos quais vivem, ou seja, o profano e o sagrado.

Podemos ainda considerar que as procissões são um meio conduzir as bandeiras, os santos e os reis. Essa sequência ritual encontrada em todas as festas da irmandade e que corresponde ao período de transporte do objeto sagrado de um lugar para outro é, por esse motivo, classificada na categoria dos ritos de margem (GENNEP, 1978, p. 155).

Nesse sentido, observei um conjunto de sequências rituais que se destacam por sua preeminência celebrativa. São preces de caráter obrigatório, realizadas por um procedimento de recitação rígida e solene que corresponde aos pedidos de licença para entrada no terreiro do congado e para entrada na casa do devoto dos santos reis. Ainda segundo GENNEP (1978), esses procedimentos como passagem material na transição do espaço da rua para o local sagrado ocorrem em função da interdição de caráter mágico-religioso normalmente expressa por marcos, muros, imagens, poste, pórtico, soleira.

Nota-se analogia entre as sequências rituais do reinado e do reisado, que começa pela passagem pela porta, em seguida pelo fundamento da bandeira, depois pelo local sagrado em que está o fundamento da festa (a lapinha ou a sede do candombe), terminando pelo local em que se realiza o cerimonial público (igreja ou a sala da casa do devoto). Desse modo, a casa do devoto dos santos reis e o terreiro do congado estabelecem limites entre o mundo estrangeiro e doméstico e o mundo sagrado e profano, pois, observa Gennep (1978, p. 37) atravessar a soleira significa entrar num mundo novo.

A experiência de comer está na ordem da experiência fundamentalmente orgânica (corporal) e, assim como a música e a dança, é sentida no paladar, na escuta, e na ação gestual. O alimento, signo digerível está presente em todas as 
festas. Como informa Callois (1989), não há festa que não comporte um elemento de pândega de excesso realizado pelo ato de comer. Se na vida cotidiana dos membros da irmandade de Justinópolis o alimento é regrado conforme as possibilidades econômicas, na festa, como também observou Freud (1974, p. 168), ele figura um excesso permitido, ou melhor, obrigatório, a ruptura solene de uma proibição.

Assim, come-se muito em todas as festas. Nas de reinado é servido café da manhã para as guardas visitantes, às vezes um jantar ou um lanche no final da tarde. O momento em que ocorre a maior distribuição de alimento, porém, é na sequência ritual do almoço de domingo. No reisado o alimento é oferecido pelo devoto, normalmente em forma de jantar ou lanche noturno; em cada casa a folia recebe algo para comer. Durante o percurso de uma noite da caravana podem ser servidos em torno de cinco lanches no período de seis horas. Pândega a que se refere Callois (1989). A sequência ritual do jantar é o único momento festivo em que os reis retiram suas máscaras. $\mathrm{O}$ ato de alimentar é procedimento de aliança e de agregação. Todos se tornam iguais diante do alimento sagrado.

Assim como o alimento, as promessas indicam procedimentos de agregação (GENNEP, 1978), sendo elementos fundamentais para a constituição das festas religiosas mineiras, já destacadas por Zaluar (1983) e Sanchis (1992); evidenciam as relações de trocas entre os festeiros e os festejados. O cumprimento das promessas possibilita estabelecimento de duplo vínculo: com a ordem divina e com a ordem dos homens.

Constituem a sequência que mais se diferencia entre os ciclos. No reinado, o pagamento das promessas é o cumprimento de uma obrigação, realizada com seriedade, o que revela o polo da magia. As guardas circulam, cantando e dançando, em torno da igreja, conduzindo o dono da promessa a pagar ao santo o atendimento a seu pedido. As guardas convidadas que recebem o almoço têm a obrigação de retribuir. No ciclo do reisado o cumprimento das promessas é realizado pelos reis que dançam para os devotos recebendo deles um pagamento em troca do espetáculo. Sempre com muito escárnio, com muito canto, e com muitos versos, essa sequência revela o polo agonístico. A sequência ritual das promessas nos coloca, em ambos os casos, diante de uma relação de troca.

\section{CONSIDERAÇÕES FINAIS}

Neste artigo não pretendi alçar análise comparativa das festas, mas ressaltar o princípio operante no circuito dos eventos e as expressões materiais que formam o ritual. Sigo desse modo, algumas considerações necessárias. 
Acompanhando as contribuições dos autores - ainda que tratem da festa em relação à sociedade, diferente do tratamento que tenho dado, pois adoto a versão de Perez (PEREZ, AMARAL, MESQUITA, 2012), de festa como perspectiva -, notamos como a festa, em sua multiplicidade de formas, evidencia a experiência singular do sagrado, fazendo-se período peculiar de transgressão da ordem e de intensa atividade coletiva.

Sinto-me inclinada a propor que as modalidades das festas de Justinópolis, semelhantes às festas de santos do estado mineiro, alternando-se possibilitam a variabilidade de experiências e produzem modos distintos de estabelecer vínculos.

A alternância foi pensada em boa medida, utilizando categorias desenvolvidas por Gennep (1978) e Turner (1967, 1969), autores que inauguram o estudo de rituais como categoria autônoma em relação a outros domínios. Assim, a dinâmica da mudança que o ritual favorece se aplica não apenas aos ritos de passagens, em que ela é estrutural, mas a todos os ritos. O rito se repete todas as vezes que ocorrem circunstâncias que o demandam (GENNEP, 1978).

A análise das informações coletadas em campo nos permite descartar uma visão de rito estática e assumir seu dinamismo, a partir da consideração de sequências rituais que compõem as diversas circunstâncias. Aqui, a ideia de sequência indica que não se devem tratar as partes do rito isoladamente, "mas na sua situação lógica, ou seja, no conjunto de seus mecanismos" (GENNEP, 1978, p. 86).

Seguindo as orientações do artigo, entendemos a estrutura ritual típica das festas do catolicismo popular brasileiro, também presente nas festas de Justinópolis. Ao examinar suas partes constitutivas - santos, bandeiras, reis, procissões, cumprimento de promessas, músicas, danças, comidas, preces -, notamos que a circulação de determinados elementos promove a alternância da festa.

Defendo assim, sob o aporte de Mauss e Bechaut (1974), que a vida social é constituída por variações e alternâncias necessárias; na sociedade esquimó essas alternâncias são facilmente notadas pelas mudanças das estações. ${ }^{5}$ Aqui, essas proposições inspiraram-me na abordagem das festas de Justinópolis. Tomadas primeiramente sob a perspectiva da variabilidade da experiência social e coletiva apontada por Mauss, notei que a alternância festiva indica fases sucessivas a que se submete a vida social e coletiva no período anual: dispêndio e reparação, repouso e atividade, agregação e separação. A variabilidade aqui implica, pois, mecanismo posicional que foi compreendido, em boa medida pelas contribuições de Gennep (1978) quando introduz a noção de alternância ritual e rota- 
tividade do sagrado. Assim a mudança que se aplica às festas ocorre todas as vezes que incidem sobre elas circunstâncias que a produzem.

Indiquei que há elementos que orientam a sucessão das sequências rituais em cada um dos ciclos separadamente, sendo análogas entre eles. Esses objetos imprimem lógica ao rito, orientando-o em sequências rituais. $E$ tal modo de organização das sequências dá forma à estrutura cíclica do ritual, produzindo mecanismo de permanente repetição da festa. Observa-se assim uma estrutura de inversão de situações e de papéis. Começamos com as muitas bandeiras que se reúnem com a mesma imagem adorada no dia da festa de reinado. Na alternância de ciclo, passamos para uma bandeira que é dispersa por toda a noite, passando pelas várias lapinhas reverenciadas. Os reis também mudam de status, deixam de ser nativos e solenes, e passam a ser cômicos e estrangeiros, em vez de exibir as coroas sagradas valem-se das máscaras, nas mãos não seguram um cetro, mas carregam uma manguara. ${ }^{6}$

Retomando a noção maussiana, vemos que os festeiros no ciclo do reinado estão produzindo a agregação. Assim o ciclo do reinado é caracterizado pela reunião no terreiro de pessoas que vão ao encontro solene dos reis que distribuem o alimento sagrado. Prevalece a agregação, o dispêndio e a introversão. A festa tende ao polo da magia. Na alternância para o ciclo do reisado, os festeiros invertem os papéis. Como visitantes, sempre em atividade tendem a separar; no lugar do dispêndio realizam a reparação; mesmo portando momentos de seriedade, a festa de reisado é extrovertida, prevalecendo o riso, a jocosidade, o polo agonístico. Na folia de reis, a chegada do filho é venerada, no ciclo do reinado, a chegada da mãe.

Tomando de outro modo os mesmos elementos do quadro, podemos sistematizar outra inversão. Chamo a atenção para a oposição das experiências vividas simultaneamente no mesmo evento pelos festeiros e pelos festejados. Se analisarmos a alternância dos elementos nos ciclos festivos sob a perspectiva do ciclo do reinado, veremos que enquanto os festeiros se fixam para receber a festa em casa, os devotos estão deslocando para festejar fora. Na alternância para o ciclo do reisado, as experiências se invertem.

Colocando essas observações em diálogo com as contribuições de Mauss e de Gennep, defendo a ideia de que a variabilidade não é uma simples circularidade, mas implica um mecanismo de mudança posicional das experiências vividas pelos festeiros e pelos festejados. Independente do ponto de referência para a observação nota-se que em as ambas perspectivas (festeiros ou festejados) há uma coexistência e uma codependência nos conduzindo de um modo ou de outro ao que está em jogo: a rotatividade do sagrado. 
No ciclo do reinado, os congadeiros e os fiéis, se reúnem e se aglomeram, portanto, o sagrado está aglutinado. Enquanto no reisado, como o nome diz, na caravana trata-se de uma peregrinação, foliões e fiéis [invertendo os papéis], simultaneamente produzem a dispersão, ou seja, o sagrado está espalhado.

Podemos assim considerar que o modo singular de associação (inversão) resulta na variabilidade e na alternância, produzindo uma rotatividade do sagrado que, por sua vez, é epifanizada pela e na festa. As diferentes sequências rituais constituem, como já dito, "causas ocasionais"- nos termos maussianos, de princípio mais geral da vida social e coletiva: a reciprocidade.

As festas não obedecem às regras da linearidade do tempo tão bem encaixadas no decurso da nossa vida social moderna, colocando de outro modo a relação com o tempo e com a própria história. Ela é pura performance, no sentido mais íntimo da palavra, pois coloca em jogo uma relação outra com a duração. Assim, o ato festivo apresenta uma realidade e uma dinâmica que lhe são próprias. Tal como o jogo, o lúdico, o sagrado e o imaginário, pertence a uma dimensão onde imperam o imprevisível e o inelutável. Refiro-me a uma experiência que abre o campo das possibilidades que envolve todos por um instante num universo desculturado que permite

às pessoas e coletividades sobrepujarem a "normalidade" e chegarem ao estado onde tudo se torna possível porque o indivíduo, então não se inscreve apenas em sua essência humana, porém em uma natureza, que ele completa pela sua experiência formulada ou não (DUVIGNAUD, 1983, p.223).

Esta, é a arte da festa, o prórpio ato de re-criação da vida.

\section{REFERENCIAS BIBLIOGRÁFICAS}

CALLOIS, Roger. O homem e o sagrado. Lisboa: Ed. 70, 1989.

CORRÊA, Juliana A. G. De reinados e de reisados: festa, vida social e experiência coletiva em Justinópolis/MG. Dissertação (Mestrado), Programa de Pós-graduação em antropologia social - UFMG, Belo Horizonte, 2009.

DAMATTA, Roberto. Carnavais malandros e heróis: por uma sociologia do dilema brasileiro. 4. ed. Rio de Janeiro: Zahar Editores, 1983.

DURKHEIM, Emile. Les formes élémentaires de la vie religieuse. Paris: PUF, 1985.

DUVIGNAUD, Jean. Festas e civilizações. Rio de Janeiro: Tempo Brasileiro, 1983.

FREUD, Sigmund. Totem e tabu e outros trabalhos. Rio de Janeiro: Imago , 1974.

GENNEP, Arnold van. Ritos de passagem: estudos sistemático dos ritos da porta e da soleira, da hospitalidade, da adoção, gravidez e parto, nascimento, infância, puberdade, iniciação, ordenação, noivado, casamento, funerais, estações, etc. Petrópolis: Editora Vozes, 1978. 
GOMES, Núbia Pereira de Magalhães; PEREIRA, Edimilson de Almeida. Do presépio à balança: representações sociais da vida religiosa. Belo Horizonte: Mazza, 1994.

MAUSS, Marcel. Ensaio sobre a dádiva. In: Sociologia e antropologia. Sao Paulo: Edusp, 1974.

.Ensaios de Sociologia. Sao Paulo: Editora Perspectiva, 1981.

MARTINS, Saul. Folclore em Minas Gerais. 2. ed. Belo Horizonte: Ed. da UFMG, 1991.

MAUSS, Marcel; BEUCHAT, Henri. Ensaio sobre as variações sazoneiras das sociedades esquimó. Sociologia e Antropologia, v. II , 1974. São Paulo: EPU.

PEREZ, Lea Freitas. Antropologia das efervescências coletivas. Dionísio nos trópicos: festa religiosa e barroquização do mundo - Por uma antropologia das efervescências coletivas. In: PASSOS, Mauro (Org.). A festa na vida: significado e imagens.. Petrópolis: Vozes, 2002.

. Por uma antropologia da festa: reflexões sobre o perspectivismo festivo. Simpósio: Festa em perspectiva e como perspectiva. XXIV Reunião Brasileira de Antropologia. Recife, 2004.

PEREZ, Léa Freitas; AMARAL, L.; MESQUITA, W.. Festa como perspectiva e em perspectiva. Rio de Janeiro: Garamond, 2012.

SANCHIS, Pierre. Arraial festa de um povo: as romarias portuguesas. Lisboa: Dom Quixote, 1992.

SOUZA, Euridiana. "E o verbo se fez canto": músicas, discursos e cultos evangélicos. Dissertação (Mestrado), Belo Horizonte, Faculdade de Música/UFMG, 2009.

TURNER, Victor. Betwixt and between: the luminal perido in rites of passage. In: . The forest of siymbols: aspects of Ndembu ritual. Ithaca and London: Cornell Universisty Press, 1967.

. The ritual process: structure and anti-structure. Ithaca, New York: Cornell University Press, 1969.

ZALUAR, Alba. Os homens de Deus: um estudo dos santos e das festas no catolicismo popular. Rio de Janeiro: Zahar, 1983.

\section{NOTAS}

1 Entrevista feita por Juliana Corrêa sobre os elementos rituais da festa de reinado. Seu Dirceu (Dirceu Ferreira Sérgio) é capitão regente da Irmandade de Nossa Senhora do Rosário de Justinópolis. Os relatos foram extraídos de entrevistas realizadas na sede da irmandade, em janeiro de 2008. Justinópolis. MG.

2 Entrevista feita por Juliana Corrêa sobre os fundamentos do reinado, a bandeira, em outubro de 2008, realizada na sede da Irmandade de Justinópolis. Ribeirão das Neves. 
3 Entrevista feita por Juliana Corrêa sobre os fundamentos do reinado, a bandeira, em outubro de 2008.

4 Seu Dirceu em entrevista a Juliana Corrêa sobre os fundamentos do reinado, a bandeira, em outubro de 2008.

5 A festa exprime as passagens. Fato corroborado num dos comentários de Van Gennep (1978, p. 151-180) a respeito do trabalho de Mauss. Ele diz que Mauss não colocou em análise as práticas em uso em decorrência da mudança climática; no entanto, elas podem ser vistas nas descrições. Por exemplo, na transição da moradia realizam-se um banquete em comum, festas na aldeia, procissões e bênçãos na saída e no regresso da passagem da vida no vale para a vida na montanha.

6 Bastão feito de madeira do tamanho de um cabo de vassoura, com guizos na extremidade superior.

Juliana Aparecida Garcia Corrêa é mestre em antropologia social pela Universidade Federal de Minas Gerais, docente na Escola Guignard/Universidade do Estado de Minas Gerais, pesquisadora no Centro de Estudos da Religião Pierre Sanchis/UFMG e membro da Associação Brasileira de Antropologia e do Sindicato dos Artistas e Técnicos em Espetáculos e Diversão.

Recebido em: 22/06/2012

Aceito em: 10/04/2013 
